\title{
CHAMBER DEPTH IN PRIMARY ACUTE GLAUCOMA*
}

\author{
BY \\ RAGNAR TÖRNQUIST \\ From the Ophthalmic Clinic, University of Gothenburg, Sweden \\ (Director: Prof. Bengt Rosengren)
}

IT is well known that there is a connexion between a narrow angle of the anterior chamber and primary acute glaucoma. As the chamber angle differs in each individual, it may often be difficult to decide how it should be classified; there is no method of measuring the angle, and it is therefore justifiable to determine a measurement which gives an indirect indication of its size. The axial chamber depth can be measured with great exactitude, and it has been shown that a small chamber depth and acute glaucoma are remarkably often coincident (Rosengren, 1931). It has also been found that the shallow chamber in acute glaucoma probably exists before the onset of the disease (Rosengren, 1931) and is genetically determined (Törnquist, 1953). This particular structure of the eye may thus be considered to be a predisposing factor in the aetiology of the disease.

However, little is known of the degree of reduction in cases of acute glaucoma or whether a difference in the predisposition can be related to varying degrees of shallowness of the anterior chamber. The following questions require consideration:

(1) What is the chamber depth at the onset of acute glaucoma?

(2) Can a crucial "threshold value" be determined, applicable to all eyes, below which the predisposition to acute glaucoma sets in?

(3) Does the risk of developing acute glaucoma increase with decreasing chamber depth?

\section{Material}

The material comprised 95 patients with primary acute glaucoma (24 males and 71 females), the total number of glaucomatous eyes being 146 . The patients were treated at the eye clinics of the Sahlgren Hospital, Gothenburg, and the Caroline Hospital, Stockholm.

\section{Methods}

Primary acute glaucoma is as a rule easy to diagnose. Sudden episodes of blurred vision, pain, and the appearance of rainbow-coloured haloes around lights are characteristic. These symptoms coincide with a considerable increase of the intra-ocular pressure. Cupping of the optic disc and impairment of the visual field appear in a late stage. Biomicroscopy and ophthalmoscopy are required in order to eliminate cases of secondary glaucoma. 
The chamber depth was measured with Stenström's apparatus. Five readings were made from the anterior surface of the cornea to the anterior surface of the lens, and five readings from the posterior surface of the cornea to the anterior surface of the lens. The real axial distance from the posterior surface of the cornea to the anterior surface of the lens was then calculated. (In comparing these results with those obtained in investigations where measurements were made only from the anterior surface of the cornea, the average thickness of the cornea - $0.57 \mathrm{~mm}$. - should be added to the values stated here.) Stenström's method and its sources of error have previously been described (Törnquist, 1953).

If not stated otherwise, the measurements were made when the intra-ocular pressure was normal.

\section{Results}

(1) Chamber Depth at the Onset of Acute Glaucoma.-The average of the chamber depth in the diseased eyes of the male and female glaucoma patients is given in Table I. The period between the onset of the disease and the time of measuring varied from a few days to 22 years (average 6 yrs).

TABLE I

CHAMBER DEPTH IN EYES WITH ACUTE GLAUCOMA

\begin{tabular}{|c|c|c|c|c|c|c|}
\hline \multirow{3}{*}{ Sex } & & \multicolumn{2}{|c|}{ Number of } & \multicolumn{3}{|c|}{ Average Chamber Depth (mm.) } \\
\hline & & \multirow{2}{*}{ Patients } & \multirow{2}{*}{$\begin{array}{l}\text { Glauco- } \\
\text { matous } \\
\text { Eyes }\end{array}$} & \multicolumn{2}{|c|}{ in Glaucomatous Eyes } & \multirow{2}{*}{$\begin{array}{l}\text { in a Random Series of } \\
\text { Normal Individuals in } \\
\text { same Age Group as } \\
\text { Glaucoma patients }\end{array}$} \\
\hline & & & & $\begin{array}{c}\text { at Time of } \\
\text { Examination } \\
\text { (measured) }\end{array}$ & $\begin{array}{c}\text { at Onset } \\
\text { (estimated) }\end{array}$ & \\
\hline $\begin{array}{l}\text { Male } \ldots \\
\text { Female }\end{array}$ & $\ldots$ & $\begin{array}{l}24 \\
71\end{array}$ & $\begin{array}{r}32 \\
114\end{array}$ & $\begin{array}{l}1.66 \pm 0.045 \\
1.59 \pm 0.026\end{array}$ & $\begin{array}{l}1 \cdot 70 \pm 0.049 \\
1.63 \pm 0.026\end{array}$ & $\begin{array}{l}\sim 2.7 \\
\sim 2.6\end{array}$ \\
\hline Total ... & $\ldots$ & 95 & 146 & & & \\
\hline
\end{tabular}

It is interesting to determine the average value at the onset of the disease, and an attempt has therefore been made to estimate the chamber depth at that time by presuming that the senile reduction is the same as in normal eyes. The size of the chamber depth of normal persons in different age 9 groups was given in an earlier paper (Törnquist, 1953) and the regression $\frac{D}{0}$ curves of the average values of the two sexes are reproduced in Fig. 1. However, it is possible that the senile reduction is not the same in persons with a $\stackrel{\sim}{\sim}$ shallow chamber, as it is likely that the genetic structure responsible for the $N$ shallow chamber is mainly manifested in old age. It is therefore possible $\underset{\mathcal{N}}{\mathcal{N}}$ that the senile reduction has developed quicker in the glaucomatous eyes and $₹$ that the estimated values of the chamber depth at the onset of the disease are consequently slightly too low. However, the average of the estimated values of the cases measured soon after onset is much the same as that of the cases measured a longer interval after onset (Table II, opposite). 
The estimated chamber depths at onset are plotted in Fig. 1. The values vary between 1.0 and $2.7 \mathrm{~mm}$., the averages for males and females being 1.70 and $1.63 \mathrm{~mm}$. respectively. The difference of $0.07 \mathrm{~mm}$. is not statistically significant.

Only eighteen of the 146 eyes (about 12 per cent.) had a chamber depth above $2 \mathrm{~mm}$.

The values seem to be independent of age

TABLE II

\section{CHAMBER DEPTH IN EYES WITH ACUTE GLAUCOMA}

\begin{tabular}{c|c|c}
\hline $\begin{array}{c}\text { Duration of } \\
\text { Glaucoma (yrs) }\end{array}$ & Number of Eyes & $\begin{array}{c}\text { Average Chamber Depth (mm.) } \\
\text { at Onset of Glaucoma } \\
\text { (estimated) }\end{array}$ \\
\hline$\leqq 5$ & 82 & $\begin{array}{c}1.61 \pm 0.032 \\
1.68 \pm 0.032\end{array}$ \\
\hline 55 & 64 & $0.07 \pm 0.045$ \\
\hline & Difference $\ldots$ & \\
\hline
\end{tabular}

Several operations had been performed earlier on many of the eyes in this series, and in some cases the eyes were under the influence of miotics at the time of investigation. It may be questioned whether these circumstances have had an effect on the size of the chamber depth.

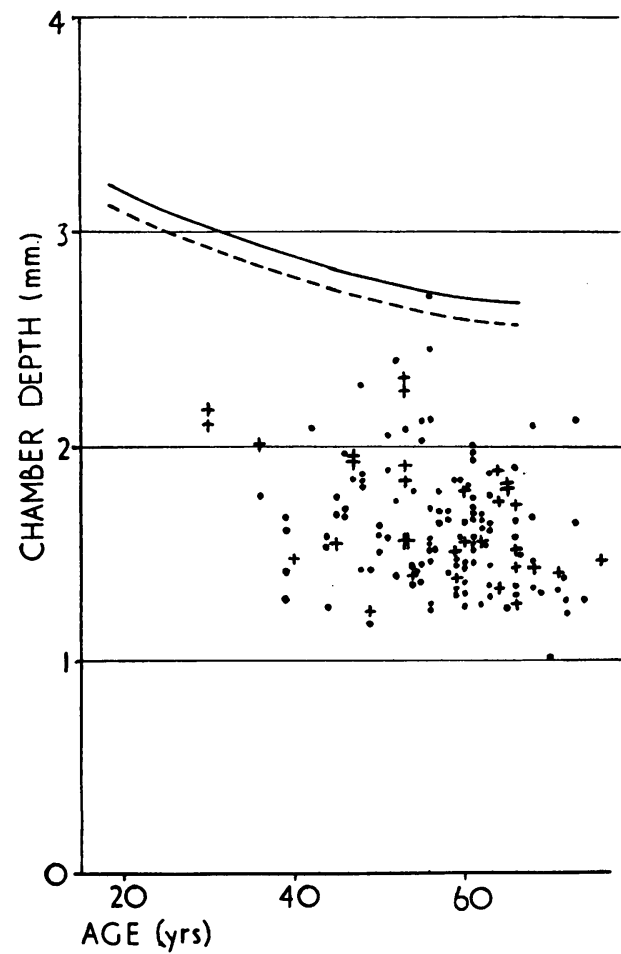

Fig. 1.-Chamber depths of glaucomatous eyes. Estimated value at onset is given for each eye. Curves indicate the average values of normal eyes at different ages for males and females.

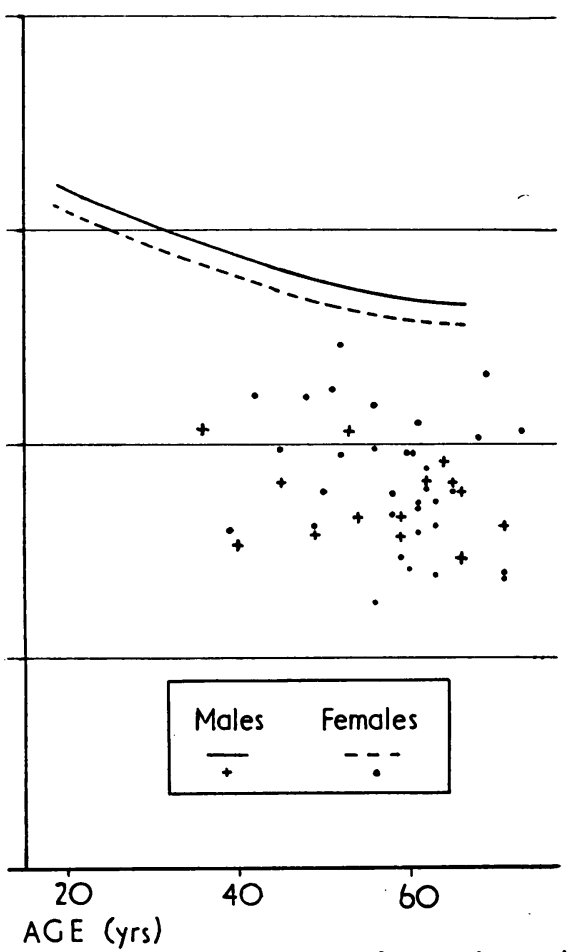

FIG. 2.-Chamber depths of normal eyes in uniocular acute glaucoma. Estimated value at onset of glaucoma of the other eye is stated. Curves indicate average values of normal eyes at different ages for males and females. 
(a) Influence of Miotics on Chamber Depth.-By administering miotics accommodation spasm occurs, followed by a thickening of the lens, and possibly results in a reduction of the axial chamber depth. Rosengren (1931) found that there was an average reduction of $0.16 \mathrm{~mm}$. in patients younger than 45 years, but that in elderly patients no change could be noticed. I have been able to confirm this in a few cases.

In the present material only seven persons were less than 50 years old when investigated and four of them ( 6 eyes) were under the influence of miotics. The chamber depth in these eyes was not lower than average; in fact higher values than the average were noticed in four eyes, and in only two were the values slightly lower than the average.

(b) Influence of Surgery on Chamber Depth.-Barkan (1954) stated that in many cases $\overrightarrow{0}$ a measurable increase in the axial depth of the anterior chamber was found to occur following iridectomy either immediately or in the course of a few months. In two patients, in both of whom both eyes had been operated on, an increase occurred of from 1.0 to 1.7 and from 1.0 to $1.6 \mathrm{~mm}$. in one patient, and from 1.2 to 1.4 or $1.5 \mathrm{~mm}$. and from 1.1 to $1.5 \mathrm{~mm}$. in the other.

In a series of twenty glaucomatous eyes on which surgery had been performed with a good result, the chamber depth was measured before and after the operation. The $N$ results are shown in Table III; no significant difference in the chamber depth is observed. Thus Barkan's observations cannot be confirmed. In a few cases a considerable reduction in the chamber depth was found in the first few days after the operation, particularly

TABLE III

CHAMBER DEPTH IN EYES WITH ACUTE GLAUCOMA BEFORE AND AFTER SURGERY

\begin{tabular}{|c|c|c|c|c|c|c|}
\hline \multirow{2}{*}{$\begin{array}{l}\text { Eye } \\
\text { No. }\end{array}$} & \multirow{2}{*}{$\begin{array}{c}\text { Age } \\
\text { of } \\
\text { Patient } \\
\text { (yrs) }\end{array}$} & \multirow{2}{*}{ Operation } & \multicolumn{2}{|c|}{ Chamber Depth (mm.) } & \multirow{2}{*}{$\begin{array}{l}\text { Time } \\
\text { between } \\
\text { Operation } \\
\text { and II }\end{array}$} & \multirow{2}{*}{ Remarks } \\
\hline & & & $\begin{array}{l}\text { Before } \\
\text { (I) }\end{array}$ & $\begin{array}{l}\text { After } \\
\text { (II) }\end{array}$ & & \\
\hline $\begin{array}{r}31 \\
86 \\
722 \\
723 \\
725 \\
766\end{array}$ & $\begin{array}{l}60 \\
60 \\
60 \\
60 \\
70 \\
64\end{array}$ & $\begin{array}{l}\text { Iridectomy } \\
\text { Iridectomy } \\
\text { Iridectomy } \\
\text { Iridectomy } \\
\text { Iridectomy } \\
\text { Iridectomy }\end{array}$ & $\begin{array}{l}1 \cdot 39 \\
1 \cdot 32 \\
1 \cdot 39 \\
1 \cdot 56 \\
1 \cdot 32 \\
2 \cdot 16\end{array}$ & $\begin{array}{l}1 \cdot 46 \\
1 \cdot 28 \\
1 \cdot 50 \\
1 \cdot 56 \\
1 \cdot 31 \\
2 \cdot 10\end{array}$ & $\begin{array}{l}1 \mathrm{mth} \\
2 \mathrm{wks} \\
3 \mathrm{wks} \\
3 \mathrm{wks} \\
1 \mathrm{wk} \\
1 \mathrm{wk}\end{array}$ & Same patient \\
\hline 767 & 46 & Iridectomy & $1 \cdot 76$ & $1 \cdot 82$ & 4 mths & $\left\{\begin{array}{l}\text { Miotics not given } \\
\text { before the measure- } \\
\text { ments }\end{array}\right.$ \\
\hline $\begin{array}{l}774 \\
792 \\
847 \\
863 \\
864 \\
877 \\
878 \\
879\end{array}$ & $\begin{array}{l}68 \\
58 \\
72 \\
59 \\
59 \\
54 \\
54 \\
56\end{array}$ & $\begin{array}{l}\text { Iridectomy } \\
\text { Iridectomy } \\
\text { Iridectomy } \\
\text { Iridectomy } \\
\text { Iridectomy } \\
\text { Iridectomy } \\
\text { Iridectomy } \\
\text { Iridectomy }\end{array}$ & $\begin{array}{l}1 \cdot 34 \\
1 \cdot 67 \\
1 \cdot 22 \\
1 \cdot 32 \\
1 \cdot 47 \\
1 \cdot 76 \\
1 \cdot 81 \\
1 \cdot 26\end{array}$ & $\begin{array}{l}1.53 \\
1.83 \\
1.15 \\
1.43 \\
1.56 \\
1.69 \\
1.85 \\
1.23\end{array}$ & $\begin{array}{l}4 \mathrm{mths} \\
2 \mathrm{mths} \\
4 \mathrm{mths} \\
1 \mathrm{mth} \\
1 \mathrm{mth} \\
2 \mathrm{wks} \\
3 \mathrm{wks} \\
1 \mathrm{wk}\end{array}$ & $\begin{array}{l}\text { Same patient } \\
\text { Same patient }\end{array}$ \\
\hline 875 & 49 & Iridectomy & $1 \cdot 49$ & $1 \cdot 50$ & 2 mths & $\left\{\begin{array}{l}\text { Equal dosage of } \\
\text { miotics given before }\end{array}\right.$ \\
\hline $\begin{array}{r}88 \\
823 \\
653 \\
654\end{array}$ & $\begin{array}{l}54 \\
64 \\
71 \\
71\end{array}$ & $\begin{array}{l}\text { Iridencleisis } \\
\text { Iridencleisis } \\
\text { Cyclodialysis } \\
\text { Cyclodialysis }\end{array}$ & $\begin{array}{l}1 \cdot 83 \\
1 \cdot 63 \\
1 \cdot 41 \\
1 \cdot 62\end{array}$ & $\begin{array}{l}1 \cdot 90 \\
1 \cdot 62 \\
1 \cdot 54 \\
1 \cdot 45\end{array}$ & $\begin{array}{l}4 \text { days } \\
1 \mathrm{wk} \\
2 \text { yrs } \\
2 \text { yrs }\end{array}$ & \} Same patient \\
\hline
\end{tabular}

Difference $(\mathrm{II}-\mathrm{I})=0.03 \pm 0.020 \mathrm{~mm}$. 
when the eye becomes hypotensive. When the tension becomes normal again the chamber depth returns to its pre-operative level. Sometimes the surface of the iris seems to become less convex after the operation.

When the average values for the operated and non-operated eyes of the whole series were compared no significant difference was found (Table IV).

Thus, it appears that the chamber depth of acute glaucomatous eyes is generally considerably reduced at the onset of the disease, the TABLE IV chamber depth being on an average $1 \mathrm{~mm}$. less than that of normal eyes at corresponding ages.

(2) Comparison between the Chamber Depths of the Two Eyes in Acute Glaucoma.-It is of interest to study the size of the chamber in the two eyes in binocular and uniocular glaucoma respectively. Material relating to the development of glaucoma in the second eye is given in Table V.

TABLE V

SECOND EYE IN 95 CASES OF ACUTE GLAUCOMA

\begin{tabular}{|c|c|c|c|}
\hline \multirow{2}{*}{\multicolumn{2}{|c|}{ 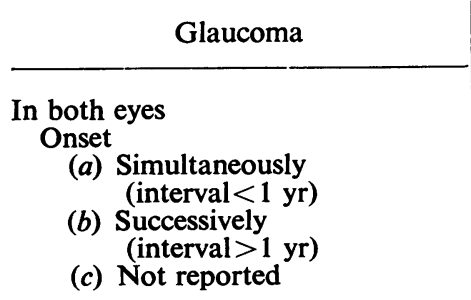 }} & \multicolumn{2}{|c|}{ Number of Patients } \\
\hline & & $\begin{array}{r}29 \\
16 \\
6\end{array}$ & 51 \\
\hline $\begin{array}{l}\text { In one eye } \\
\text { Observation Time after } \\
\text { (a) }<5 \text { yrs } \\
\text { (b) }>5 \text { yrs }\end{array}$ & Onset & $\begin{array}{l}15 \\
23\end{array}$ & 38 \\
\hline Only one eye measured & $\ldots \quad \ldots$ & - & 6 \\
\hline Total & $\ldots \quad \ldots$ & - & 95 \\
\hline
\end{tabular}

(a) Binocular Acute Glaucoma.-In cases of binocular glaucoma in which both eyes developed the disease simultaneously (t he difference in time being less than 1 year), a very sma 11, insignificant difference $(0.01 \mathrm{~mm}$.) was found between the measured chamber depths of the two eyes (Table VI, overleaf), being about the same as that seen in normal persons $(0.05 \mathrm{~mm}$.; Törnquist, 1953). In cases in which the disease developed in the second eye more than one year after the first the chamber is usually shallower in the first eye; the average difference $(0.09 \mathrm{~mm}$.) is probably significant statistically. If the average estimated value at the onset of the disease in the two eyes is calculated, a smaller difference is obtained 
TABLE VI -

CHAMBER DEPTH IN BINOCULAR ACUTE GLAUCOMA

\begin{tabular}{c|c|l|c|c}
\hline Onset & $\begin{array}{c}\text { Number of } \\
\text { Patients }\end{array}$ & Eye & $\begin{array}{c}\text { Average Chamber } \\
\text { Depth (mm.) }\end{array}$ & Difference \\
\cline { 2 - 5 } $\begin{array}{c}\text { Simultaneously } \\
\text { (interval }<1 \text { yr) }\end{array}$ & 29 & $\begin{array}{l}\text { Right } \\
\text { Left }\end{array}$ & $\begin{array}{c}1.65 \pm 0.060 \\
1.66 \pm 0.057\end{array}$ & $\mathbf{0 . 0 1 \pm 0 . 0 2 4}$ \\
\hline $\begin{array}{c}\text { Successively } \\
\text { (interval }>1 \text { yr) }\end{array}$ & 16 & $\begin{array}{c}\text { First } \\
\text { contracted } \\
\text { Last } \\
\text { contracted }\end{array}$ & $1.47 \pm 0.053$ & $0.09 \pm 0.036$ \\
\hline
\end{tabular}

$(0.05 \pm 0.041 \mathrm{~mm}$.$) . Thus it appears that the second eye developed the disease$ when, by senile reduction, its chamber depth had become similar to that obtaining in the first eye at the time of onset; but it is not possible to draw any positive conclusions from this small series.

(b) Uniocular Acute Glaucoma.-In cases in which at the time of investigation only one eye was glaucomatous, the chamber depth of the diseased eye was similar to that of the whole series of glaucomatous eyes. But a reduction was also present in the healthy eye; the deviation from the random sample of normal eyes is shown in Fig. 2 (p. 423) and Table VII. The deviation is statistically significant.

TABLE VII

COMPARISON BETWEEN DISTRIBUTION OF A SERIES OF RANDOM CASES AND OF A SERIES OF HEALTHY EYES IN UNIOCULAR ACUTE GLAUCOMA AT THE LIMITS GIVEN BELOW

\begin{tabular}{|c|c|c|c|c|c|}
\hline \multirow{2}{*}{$\begin{array}{c}\text { Below Limit } \\
\text { (M=Mean in } \\
\text { Random Series) }\end{array}$} & \multicolumn{2}{|c|}{$\begin{array}{c}\text { Random Eyes } \\
n_{1}=398\end{array}$} & \multicolumn{2}{|c|}{$\begin{array}{c}\text { Healthy Eyes in } \\
\text { Uniocular Glaucoma } \\
n_{2}=47\end{array}$} & \multirow{2}{*}{$\begin{array}{l}\text { Difference } \\
\left(P_{2}-P_{1}\right) \pm \\
\pm \epsilon_{\left(P_{2}-P_{1}\right)}\end{array}$} \\
\hline & $\begin{array}{c}\text { Number } \\
z_{1}\end{array}$ & $\frac{100 z_{1}}{=n_{1}}=P_{1}$ per cent. & $\underset{z_{2}}{\text { Number }}$ & $\frac{100 z_{2}}{=n_{2}}=P_{2}$ per cent. & \\
\hline $\begin{array}{l}M-3 \sigma \\
M-2 \sigma \\
M-1 \cdot 5 \sigma\end{array}$ & $\begin{array}{r}3 \\
11 \\
30\end{array}$ & $\begin{array}{l}0 \cdot 8 \\
2 \cdot 8 \\
7 \cdot 5\end{array}$ & $\begin{array}{l}28 \\
38 \\
45\end{array}$ & $\begin{array}{l}59 \cdot 6 \\
80 \cdot 9 \\
95 \cdot 7\end{array}$ & $\begin{array}{l}58 \cdot 8 \pm 7 \cdot 2 \\
78 \cdot 1 \pm 13 \cdot 9 \\
88 \cdot 2 \pm 3 \cdot 2\end{array}$ \\
\hline
\end{tabular}

TABLE VIII

CHAMBER DEPTH IN UNIOCULAR ACUTE GLAUCOMA

\begin{tabular}{c|l|c|c}
\hline $\begin{array}{c}\text { Number of } \\
\text { Patients }\end{array}$ & \multicolumn{1}{|c|}{ Eye } & $\begin{array}{c}\text { Average Chamber } \\
\text { Depth (mm.) } \\
\text { (measured) }\end{array}$ & Difference \\
\hline \multirow{2}{*}{47} & Glaucomatous & $\begin{array}{c}1 \cdot 61 \pm \mathbf{0 . 0 4 2} \\
1.77 \pm \mathbf{0 . 0 3 8}\end{array}$ & $0.16 \pm \mathbf{0 . 0 2 9}$ \\
\hline
\end{tabular}

The average difference between the chamber depths of the healthy eye and the diseased eye is $0 \cdot 16 \pm 0.029 \mathrm{~mm}$. and is thus statistically significant ( $\mathrm{Tab}$ le VIII).

For the following reasons it seems unlikely that the disease contributes to the reduction of the chamber depth: 
Out of 47 cases in which at the first investigation only one eye was glaucomatous, nine patients later developed glaucoma in the other eye as well. Of the remaining 38 cases, fifteen had been under observation for less than 5 years, and 23 for more than 5 years since the onset. If these two groups are compared, the average difference between the eyes is found to be a little less in the latter group. However, statistically, there is no difference between the groups (Table IX). In the five cases in which more than 15 years had passed since the onset and the other eye was still healthy, the differences were $0.07,0 \cdot 15,0 \cdot 16,0 \cdot 17$, and $0.19 \mathrm{~mm}$. If the disease had an effect on the chamber depth one would expect the difference to be greater in the cases of longer duration.

TABLE IX

CHAMBER DEPTH IN UNIOCULAR ACUTE GLAUCOMA

\begin{tabular}{c|c|l|c|c}
\hline $\begin{array}{c}\text { Observation } \\
\text { Time } \\
\text { (yrs) }\end{array}$ & $\begin{array}{c}\text { Number of } \\
\text { Patients }\end{array}$ & \multicolumn{1}{|c|}{ Eye } & $\begin{array}{c}\text { Average Chamber } \\
\text { Depth (mm.) }\end{array}$ & Difference \\
\hline$<5$ & 15 & Glaucomatous & $\begin{array}{r}1.59 \pm 0.076 \\
1.78 \pm 0.082\end{array}$ & $0.19+0.078$ \\
\hline \multirow{2}{*}{23} & Healthy & Glaucomatous & $1.68 \pm 0.064$ & $0.15 \pm 0.031$ \\
\hline & Healthy & $1.83 \pm 0.049$ & $0.04 \pm 0.084$ \\
\hline
\end{tabular}

The difference in chamber depths between the two eyes in uniocular glaucoma can be explained by the fact that the chamber depth of the diseased eye is less than that of the healthy eye even before the onset of the disease. Cases of primarily uniocular glaucoma are thus likely to include those in which, even before the onset, the chamber depths of the two eyes were not equal. Consequently the eye with the shallower chamber would seem to be more prone to the disease.

\section{Comment}

A shallow anterior chamber is very important for the development of acute glaucoma. According to this investigation, the axial chamber depth at the onset of the disease was about $1 \mathrm{~mm}$. less than in normal cases, or two-thirds of the normal depth at corresponding ages. Typical cases of acute glaucoma have almost without exception a markedly reduced chamber depth, but there is much variation, and it is not possible to determine a crucial "threshold value" below which the risk of acute glaucoma appears.

Cases of simple glaucoma show a normal variation in chamber depth, and a value similar to that in acute glaucoma is sometimes found (Rosengren, 1931). Therefore it is difficult to determine a limiting value separating cases of acute and simple glaucoma.

Probably the degree of reduction of the anterior chamber is of importance in the pathogenesis of glaucoma. On the basis of his examinations, Posner (1955) supposed that peripheral iris crypts play an important role in safe- 
guarding the eye with a narrow chamber angle from acute attacks. These $\frac{\vec{D}}{\bar{J}}$ are supposed to appear in the healthy eye in uniocular glaucoma. However, the observed difference in chamber depth between the two eyes in this type $\overrightarrow{\vec{F}}$ of case probably explains the difference in predisposition to glaucoma.

A thorough analysis of the risk of developing glaucoma at different degrees $\frac{7}{5}$ of reduction of the chamber depth should be of great interest. This requires $\frac{\bar{m}}{\bar{m}}$ reliable records of all cases of acute and prodromal glaucoma in the same $\stackrel{\odot}{\stackrel{\odot}{\varrho}}$ population, which is difficult to obtain. Table $\mathrm{X}$ indicates the relative risk at different chamber depths, showing that the risk of acute glaucoma in- $\overrightarrow{0}$ creases with decreasing chamber depth.

TABLE $\mathrm{X}$

CALCULATION OF RISK OF CONTRACTING ACUTE GLAUCOMA AT DIFFERENT LEVELS OF CHAMBER DEPTH

\begin{tabular}{c|c|c|c|c|}
\hline $\begin{array}{c}\text { Chamber Depth } \\
(\text { mm.) }\end{array}$ & $\begin{array}{c}\text { Number of } \\
\text { Glaucomatous } \\
\text { Eyes * } \\
(a)\end{array}$ & $\begin{array}{c}\text { Calculated Number } \\
\text { of Normal Persons } \\
\text { in Gothenburg } \dagger \\
(\text { total 292,796) } \\
(n)\end{array}$ & $\begin{array}{c}\text { Frequency } \\
\frac{a}{n}\end{array}$ & Morbidity Risk + \\
\hline $2.5-2.0$ & 16 & 28,900 & 0.00055 & 1 \\
$2.0-1.5$ & 77 & 800 & 0.09625 & 175 \\
$1.5-1.0$ & 52 & 1 & 52 & 94,545 \\
\hline
\end{tabular}

* The material was collected in Gothenburg and Stockholm, and the onset in almost every case had occurred in the years $1930-1950$.

t The calculation of the number of normal persons in the different classes of chamber depth was made on the basis of the distribution found in the random series of 398 normal cases. It was then assumed that there is a normal distribution with a standard deviation of $0.28 \mathrm{~mm}$. in every age decade. The relative number below a certain limit can then be obtained from statistical tables in common use. The absolute number of each sex was calculated from the average population of both sexes in different age decades during the years 1930-1950 in Gothenburg.

$¥$ Let the risk of contracting the disease at a chamber depth between $2 \cdot 5$ and $2 \cdot 0 \mathrm{~mm}=1$.

A difference in the degree of narrowness of the chamber angle seems to be important in estimating the risk of developing acute glaucoma. If the disease is manifest, it is difficult to estimate the significance of a chamber angle merely from the fact of its being narrow, a very narrow angle is more important in pathogenesis than a moderately narrow angle.

Little is known of the causes of the shallow chamber and the narrow angle. The lens may protrude or may be abnormally large in proportion to the corneo-scleral capsule. On the basis of his observations of enucleated eyes, Priestley Smith (1911) advanced the latter hypothesis, though during a rise in intra-ocular pressure a slight protrusion could also be observed-no measurements were made.

Clearly normal post-operative conditions do not lead to an increase in the depth of the anterior chamber. The chamber depths in seven cases in this series were measured before and during the rise in pressure and no significant difference was observed. Any displacement of the lens which may occur seems to be invariable or to vary only slightly. An increase of the size of 
the lens is perhaps more probable, but direct measurements of the thickness of the lens in vivo in acute glaucoma have not yet been made.

By this investigation it is impossible to elucidate the structure of the mechanism at the onset of hypertension in eyes with a shallow chamber; there may be other important causative factors.

\section{Summary}

(1) The axial chamber depth in acute glaucoma is less than that in normal eyes, and is estimated at the onset of the disease to be on an average $1.70 \mathrm{~mm}$. in males and $1.63 \mathrm{~mm}$. in females, i.e. about two-thirds of the normal depth.

(2) In binocular acute glaucoma, it is found that:

(a) When the two eyes develop the disease simultaneously no significant difference between the chamber depths is observed.

(b) When the two eyes develop the disease successively the chamber depth of the first eye to be affected is less than that of the second eye, the difference being statistically significant.

(3) In uniocular acute glaucoma, it is found that:

(a) The chamber depth of the healthy eye is less than that in a random sample of eyes, the difference being statistically probable.

(b) The difference between the chamber depths of the two eyes is statistically significant, the glaucomatous eye showing the greatest reduction.

(c) The cause of this difference probably lies in an inequality between the two eyes which existed even before the onset of the disease.

(4) There is a difference in the degree of predisposition in different chamber depths, and shallower chambers carry an increased risk of developing acute glaucoma.

\section{REFERENCES}

BARKAN, O. (1954). Amer. J. Ophthal., 37, 504.

POSNER, A. (1955). Ibid., 40, 469.

ROSENGREN, B. (1930). Acta ophthal. (Kbh.), 8, 99.

- (1931). Ibid., 9, 103.

Smith, Priestley (1911). Ophthal. Rev., 30, 97.

TÖRNQUisT, R. (1953). Acta ophthal. (Kbh.), Suppl. 39. 